\title{
ISO 9000 QUALITY ASSURANCE CERTIFICATION IN THE MINING SECTOR OF GREECE K.P. KITSOPOULOS ${ }^{1}$, P.W. SCOTT ${ }^{2}$ AND C.A. JEFFREY ${ }^{3}$
}

\begin{abstract}
All over the world, businesses have started moving towards Quality Assurance and the adoption of ISO 9000 Standards. In this study, we examined the status of the Quality Assurance Certification of companies which operate in the mining sector in Greece. It is certain that the companies have started working towards Quality Management and Quality Assurance Certification. The movement towards Quality Assurance is customer driven. The specific motives for implementing Quality Assurance Certification were customer satisfaction, to gain a competitive advantage and improve business efficiency. They anticipate a better business image, to increase customer satisfaction and strengthen their market share. The level of criticism for some aspects of the ISO 9000 certification, which has been recorded in other parts of the world, was not found in Greece. Following the introduction of ISO 9000, some mining companies also included in their strategy the introduction of ISO 14000 which relates to Environmental Management Systems.
\end{abstract}

KEY WORDS: Total Quality Management, Quality Assurance, ISO 9000, Environmental Management Systems, ISO 14000, Mining Sector, Mineral Resources, Greece.

\section{INTRODUCTION}

"Prevention, not inspection" is the cornerstone in the philosophy of Quality Assurance.

Following the publication of the International Standards Organization (ISO) 9000 Standards in 1987, Quality Assurance and Quality System Certification have enjoyed widespread recognition in industry. Almost 150 countries across the world have now adopted ISO 9000 . Worldwide, the number of the ISO 9000 certificates is still growing. About 71,796 new ISO 9000 certificates were awarded during the period December 1998-December 1999, representing an increase of $26.4 \%$ (ISO, 2000). From the 27,816 ISO certificates in January 1993 in just 48 countries, we have reached 343,643 certificates worldwide in December 1999(ISO, 2000). In Greece, 18 certificates were available in January 1993; 1050 were possessed by the end of December 1999. ISO and European Standards EN 45000 series are also important for the policy of the European Union concerning the circulation of goods among the EU countries. At the present time an ISO 9000 certificate from an accredited Certification Body is much sought after, as companies seek to gain market advantage and to comply with their customers' requirements.

In today's business environment and with increasing competition, managers must strive for competitive advantage in order to hold their market share. Consumers have started to give a high value to quality alongside traditional loyalty and price. The last two factors have almost ceased to be the major determinant in consumer's choice. Price now competes with quality and that applies to all kinds of business and service enterprises. Furthermore, consumers have even greater expectations and apply more sophisticated criteria in their purchases. This is the reason why research goes on regarding customer's shopping behavior and how customer thinks when making a choice. It is not surprising then that businesses have started to regard Quality Assurance as a necessity to survive (Marash and Marquardt, 1994).

The scope of this study was the investigation of the status of Total Quality Management and more specifically the ISO 9000 Quality Assurance Certification in the mining sector of Greece.

1. Geology Department, Leicester University, Leicester, LE1 7RH, UK. Correspondence to: 16 Aiolou Str., P. Faliro, 175 61, Athens, Greece.

2. Camborne School of Mines, Exeter University, Cornwall, UK.

3. Geology Department, Leicester University, Leicester, LE1 7RH, UK. 


\section{TERMS OF REFERENCE}

\subsection{Quality and Quality Assurance}

The term 'Quality' is used to express 'nothing less than specification' and not to be concerned with whether or not a particular product or service is aimed at the luxury end or the bottom of the market (Crosby, 1984). Therefore, Quality should signify the 'excellency' of a product or a service.

This term was used for the first time in the literature in 1959 when the American Ministry of Defense (DOD) published the MIL-Q-9858, 'Quality Program Requirements'. This standard covered conventional obligations of the creation of Quality programs for the suppliers of products and services to the American Army.

Nowadays, a major problem in businesses of the manufacturing and the service sector is that throughout and between organizations, there are a series of quality chains which may be broken at any point due to a person or a process failing to meet the requirements of the internal or external customer. This failure is multiplied as a failure in one part of the system creates problems elsewhere. The price of quality is the continuous examination of the requirements and our ability to meet them (Oakland, 1993).

The role of Quality Assurance is mainly preventive. 'Quality Assurance' is the prevention of Quality problems through planned and systematic activities including documentation (Oakland, 1993). These will include the establishment of a good Quality Management System and the assessment of its adequacy, the audit of the operation of the system and the review of the system itself' (Oakland, 1993 Part: 16).

Nevertheless, as a relatively new term, Quality Assurance has brought about many misconceptions, the most common of which are (Stebbing, 1993):

a. It is not quality control or inspection

b. It is not a super-checking activity

c. It is not responsible for engineering decisions

d. It is not a massive paper generator

e. It is not a major cost area

d. It is not a panacea for all ills

Instead Quality Assurance is:

a. Cost-effective

b. An aid to productivity

c. A means of getting it right first time every time

d. Good management sense, and most importantly

e. The responsibility of everyone.

\subsection{ISO 9000 standards' series}

ISO 9000 series is a set of five individual, but related, international standards on Quality Management and Quality Assurance. They are generic, not specific to any particular products. Used by manufacturing and service industries alike, they were developed to effectively document the quality system elements to be implemented in order to maintain an efficient quality system in businesses. The standards will ensure that the final product or service delivered to the customer complies with the relevant specifications. ISO 9000 provides the user with guidelines for selection and use of ISO 9001, 9002, 9003 and 9004. ISO 9001, 9002, and 9003 are quality system models for external Quality Assurance. ISO 9001 - the most comprehensive - is covering design, manufacturing, installation and servicing systems. ISO 9002 covers production and installation. ISO 9003 covers only final product inspection and test. These three models were developed for use in contractual situations such as those between a customer and a supplier. ISO 9004 provides guidelines for internal use by a producer developing its own quality system to meet business needs and take advantage of opportunities.

\subsection{The mining sector of Greece}

The mining sector of Greece is a concentrated industrial sector. Almost $60 \%$ of the sector's turnover is handled by five mining companies (Newman, 1998). A great part of the activities of the sector are related to the mining, processing and trading of industrial minerals and rocks and their products. In Greece, perlite, bentonite, pumice, magnesite, and marble are some of the main products. Greece is an international key player for perlite and bentonite and the largest exporter of magnesite in EU. Also, it is among the top ten producing countries worldwide with respect to marble, having some of the finest quality materials. The activities of the sector also include a considerable exploitation of Fe-Ni ores and bauxite, for which Greece is the largest producer of EU. 
More specifically for $\mathrm{Ni}$, it covers $2-3 \%$ of the world's Ni demand (exported as Fe-Ni ores). Coal is the major energy resource. Lately, there are plans for the production of $\mathrm{Au}$ too. The sector has a strong export orientation; $50 \%$ of the total production. In 1998, these exports accounted for the $5.3 \%$ of Greece's total export (Chalikias and Pinotsi, 2000). In 1999, the total production, including coal, was almost 73 million tons of materials, and the value of the exported materials was almost 123 billion drs (GMEA, 2001). For the purpose of this study, companies producing cement were included in the sector because a) the production of the cement mainly requires the extensive use of clays, limestone and volcanic materials, b) most of the companies operate their own quarries for the production of these materials, and c) in many industrial sector studies these companies are usually included in the mining sector. Greece is among the top five cement producing countries in EU. The cement companies have a strong export orientation, controlling a significant amount (20\% in 1996) of EU's exports. Overall, the mining sector is one of the most important industrial sectors of Greece, contributing 1,7\% to the NGP of Greece (Newman, 1998). The above mineral commodities are in many cases the processed counterparts of the relevant naturally occurring materials. The latter are created by a series of complex geological, mineralogical and geochemical procedures. Therefore, in terms of Quality Assurance Certification, this means that many problems may occur because of the special nature of the starting mined materials. The desired product is not an industrial commodity, on which Quality Assurance rules may apply more easily. The concentration of the mineral in question may greatly vary in the materials mined and, therefore, these materials often contain unwanted impurities, capable of deteriorating the desired properties of the final product. Also, the physical and chemical properties of the mineral in question may change throughout the deposit. Under these conditions the exploitation of such materials may cause problems over time that make it much more difficult to apply the actions of Quality Assurance.

\section{METHODOLOGY}

Data collection in management issues studies such as a Quality Assurance Certification scheme, is not a wholly scientific exercise. It does not follow the route "experiment, results, interpretation". In management fields, the choices in executing an investigation and acquiring data are: Action research (on the spot procedure), the Case Study approach (focus on inquiry around an instance), the Ethnographic style (observing behaviors by total integration in the given society), Surveys (posing the same questions to a number of individuals) and the Experimental style (controlled experiments). In this study, the Survey method was mainly followed using a purpose designed questionnaire. The study was coupled with elements of an Action type of research through the collection of opinions and comments made by those people responsible in each company for Quality Assurance matters.

\section{RESULTS}

The survey took place during the period between 1995-1997. Twenty-six questionnaires were sent to companies in the mining sector of Greece. Twenty-one of them were answered. For the purpose of this study, companies holding some form of ISO Quality Assurance Certification are referred to as "certified". Companies referred to as "pursuing" are those that have started the necessary procedures to obtain Certification, and their relevant projects are in various stages, from starting up to near completion. Finally, "uncertified" are the ones that do not have any form of Certification and do not intend to seek Certification in the near future. The relevant distribution of the companies in the mining sector of Greece is shown in Figure 1. Six companies (28.6\%) hold some form of ISO 9000 Certification. Ten companies (47.6\%) can be characterized as "pursuing" companies as they were found to have started procedures to obtain ISO Quality Assurance Certification, and five other companies $(23.8 \%)$ can be referred to as uncertified.

The motives, which according to respondents (certified and pursuing companies) seemed to be the most important for obtaining or working towards Quality Assurance Certification, and the analysis of the benefits expected for the same group of companies are given in Figure 2. 


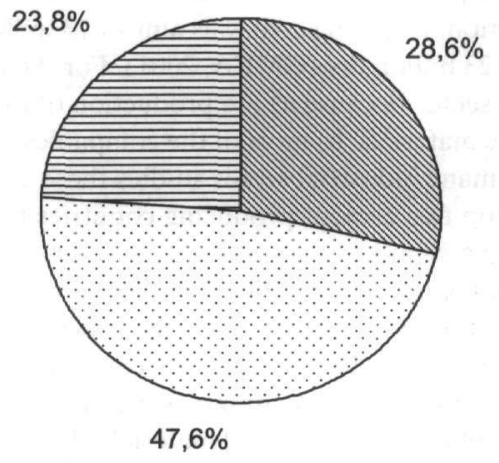

Figure 1. Distribution of Greek mining companies with respect to their ISO 9000 Quality Assurance Certification status.

\section{DISCUSSION}

The majority of the companies (over $75 \%$ ) can be considered as certified or pursuing companies. The certified companies (Table 1) include some of the largest in the mining sector of Greece. They are all companies with strong export orientation and some of them known worldwide for their products. They were amongst the first to introduce Quality issues within the working environment and are generally very keen to increase Quality Awareness within their establishments.

Table 1. Companies in the Greek mining sector holding some form of ISO 9000 Quality Assurance Certification.

\begin{tabular}{|c|c|c|c|}
\hline COMPANY & $\begin{array}{c}\text { ISO } \\
\text { CERTIFICATION }\end{array}$ & $\begin{array}{c}\text { CERTIFICATION } \\
\text { DATE }\end{array}$ & CERTIFYING BODY \\
\hline ALUMINIUM OF GREECE SA & $\begin{array}{l}9002 \\
9002\end{array}$ & $\begin{array}{l}20-01-1995 \\
29-03-1993\end{array}$ & $\begin{array}{l}\text { ELOT } \\
\text { ELOT }\end{array}$ \\
\hline GMMSA \& LARKO & 9002 & $27-06-1994$ & ELOT \\
\hline GRECIAN MAGNESITE SA & 9001 & $13-06-1995$ & ELOT \\
\hline IKTINOS HELLAS SA & 9002 & $22-07-1997$ & ELOT \\
\hline MARBLE OF GREECE & 9002 & $22-02-1995$ & BUREAU VERITAS \\
\hline & & & 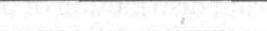 \\
\hline $\begin{array}{l}\text { SILVER AND BARYTE ORES } \\
\text { SA }\end{array}$ & 9002 & $06-04-1994$ & BUREAU VERITAS \\
\hline
\end{tabular}

The strong movement of the companies of the Greek mining sector towards ISO 9000 certification is in accordance with data for similar companies around the world. ISO (2000) has recorded an increase of $70 \%$ in ISO 9000 certificates between 1998 and 1999 in the Mining and Quarrying Industrial Sector (EAC Code Nos. 2), $53.4 \%$ increase in the Non-metallic mineral products Industrial Sector (EAC Code Nos. 15) and an increase of $42.2 \%$ in the Concrete, cement, lime, plaster, etc Industrial Sector (EAC Code Nos. 16). Up to date information on companies of the mining sector holding ISO 9000 certificates can be found through ELOT (http://www.elot.gr) and BUREAU VERITAS (http://www.bureauveritas.gr).

The majority of the certified and pursuing companies have quoted customer satisfaction as their strongest motive $(94 \%)$. At the same time competitive advantage (83\%) and business image $(67 \%)$ are also frequently stated 
as important factors. The need for Quality Assurance Certification in the specific sector was clearly customer driven.

The majority of the companies surveyed agreed that their customers have dragged them or will in the future keep dragging them towards Quality. These motives are in agreement with what has been already reported in the literature. In addition to the literature, the data shows that for companies of this type, business efficiency is widely considered as a serious motive for working towards Quality Assurance. As it was mentioned by a large number of people, responsible for the implementation of Quality Assurance projects within the respective companies, these actions provided an excellent opportunity to reassess and review a number of procedures and systems within the working environment. Market image, which was picked by $89 \%$, and customer satisfaction, picked up by $83 \%$ of the respondents, are the two most important benefits that Quality Assurance Certification is expected to bring to the company. So, Certification is not only customer driven, but customer focused too. Profitability, exports and an increase in quality awareness, although not among the major ones, were picked up by almost one third of the respondents. Benefits related to exports were mainly related to large companies.

The four major problems that companies faced during the process of seeking Certification were equally concerned with internal and external factors. Regarding internal problems, the lack of experience and the resistance met, nowadays referred to as the "we have been always working that way" syndrome, were pointed to as major issues. There is no doubt that in principle a quality management system is all about managing change and in the literature many difficulties have been reported in managing change successfully. If change is to be realized, it needs understanding, support and involvement from the top management.

As far as the external factors are concerned, people responsible within the companies for Quality issues tend to agree that the Standard's terminology creates interpretation problems. The Certification procedure is conceived as rather bureaucratic and the "language" used as rather unfriendly. Similar difficulties in the implementation of BS 5750 were pointed out by Whittington (1989). Its 'unfriendliness' is due to its need for application to a wide spectrum of business and as such it has to be stated in rather general terms. The issue of poorly trained people, so called "Quality Consultants", was also greatly acknowledged as a problem, especially from small companies. Companies are not reluctant to comment on the inefficiency of their consultants even if they are working at the moment with them and the results are not known yet. This fact indicates the need for more, well trained individuals or consultant groups in Greece who can successfully help companies work towards Certification.

Smaller companies comment strongly on the cost of obtaining the certification and they believe that these costs are in excess of the forthcoming benefits. It is true that it is difficult to give an exact estimate of the cost, as this will depend on the size of the company and the complexity of its operations, whether or not any form of quality system exists and on how many procedures are to be written and implemented. In general, the cost is divided into two categories: a) the cost of applying the principals of ISO 9000 , including the cost of any advice on how it should be done and on whether it has been done successfully and b) the cost of obtaining and maintaining a certificate of that fact which suppliers are prepared to rely on. The first category can be regarded as capital expenditure (Stebbing, 1993). After the initial capital expenditure, the cost declines rapidly and the costs associated with maintaining the system should remain at a reasonable level. The savings made due to the implementation will rise initially and then remain effective so long as the system is implemented. It is obvious that for small businesses, as the ones referred to here, this initial capital expenditure is a difficult step to take.

All pursuing companies asked that the data provided remained absolutely confidential and their names not be disclosed. This fact indicates that the companies operate in a highly competitive environment and since Quality Assurance Certification is highly considered as a competitive advantage, they would not like to disclose their strategic plans to competitors and lose any of the expected advantage. A large number of companies was categorised as uncertified and had no intention to seek Quality Assurance Certification. This is to be expected since the sector includes a considerable number of small companies especially in the area of marbles and aggregates production. However, given the intense competition in the sector, it is quite possible that companies which stated no interest or no intention in obtaining Certification, could actually be working on it, but would not like to reveal it. They may also worry about the success of a relevant ongoing project, as not all companies are proved successful in obtaining certification, and they would not like to risk their business image in case of a failure.

Internationally, a growing criticism against the ISO 9000 has been identified within the business world, mainly due to its failure to lead directly to better quality products, the poor training of consultants and the tendency to develop a quality management system just for the marketing logo on the company's letterhead (Burgess, 1993). However, the results of the present study, among companies in the Greek mining sector, do not confirm such a level of criticism. Although problems were certainly identified, all the Quality managers in the sector strongly support the important anticipated contribution of ISO 9000 to their business and consequently 
its great need. It is interesting, though, that $84 \%$ of the respondents consider that the overall level of quality in the Greek mining sector is still only moderate.

Mining companies operate under strict legal regulations regarding the impact of their operations on the environment. In addition, it is inevitable the nature of their works to rise problems between the companies and their environmental practice and behavior, and the general public. It is anticipated that companies which implemented and got familiar with ISO 9000 certification have an excellent chance to benefit greatly from the introduction in the 90's of the ISO 14000 standards. This is because, the ISO 14000 standards take much of their approach, structure and inspiration from the ISO 9000 . ISO 14000 is a series of standards on environmental management systems (EMS) and tools. ISO 14000, along side EMAS (Eco-Management and Audit Scheme) which was initiated by the EU, will deal with a company's system for managing its day-to-day operations as they have an impact on the environment. So, the establishment and implementation of an organisation's EMS is of central importance in determining the organisation's environmental policy, objectives, and targets. It is important to note that comments received from some of the companies during the period of this study indicated their intention to work towards ISO 14000 too. Considering the fact that in December 1999 there were only 20 companies in Greece, from all business sectors, accredited with ISO 14000 (ISO, 2000), the mining companies in Greece holding ISO 14000 could be consider among the pioneers in this area. This could possibly change the way the public accepts such operations and minimise relevant problems.

\section{CONCLUSIONS}

The results of this research show that a clear trend towards the introduction of Quality Assurance Certification has been established among the mining companies in Greece. They move alongside their counterparts around the world towards ISO Quality Assurance Certification. In general, Quality Assurance Certification is perceived as a major qualification for the future and mining companies in Greece expect to take full advantage from their involvement with Quality Assurance Certification. At the same time, it seems that they have also realize that an ongoing fight is needed every day to keep Quality Awareness mentality alive within the working environment. In terms of an attentive search for Quality and the responsibilities of the management the words by Sakofsky (1994) are decisive: "Survival after ISO 9000 registration will only happen if the organization switches from meeting the minimum ISO 9000 quality system requirements to satisfying business requirements. There will never be a substitute for satisfaction that results from shipping a product that exceeds the expectation of the customer and meets the cost constraints of the manufacturer".

\section{REFERENCES}

BURGESS, N. (1993) A critical review of Quality Management developments. Proceedings of a Conference on Quality Management Strategy - The Future, Westminster, London.

CHALIKIAS, I. AND PINOTSI, D. (2000). The basic exportable products of Greece in 1998. Hellenic Association of Exporters.

CROSBY, P.B. (1984) Quality without tears. Mc Graw Hill Book Company, New York.

GMEA (Greek Mining Enterprises Association) (2001). Activity Report for 2000.

MARASH, S.A. AND MARQUARDT, D.W. (1994) Quality standards and free trade. Quality Progress.

NEWMAN, R.H. (1998). The Mineral industry of Greece. USGS.

ISO (2000). The ISO survey of ISO 9000 and ISO 14000 Certificates. The International Organization for Standardization. Switzerland.

OAKLAND, J.S. (1993) Total Quality Management. Heinemann, Oxford. 2nd ed.

SAKOFSKY, S. (1994) Survival after ISO 9000 registration. Quality Progress, pp 57-59.

STEBBING, L. (1993) Quality Assurance. Ellis Horwood Lim., 3rd ed., England.

WHITTINGTON, D. (1989) Some attitudes to BS 5750: A study. International Journal of Quality and Reliability Management, 6, 3, pp 54-58. 